\title{
HYPOTHETICAL LEARNING TRAJECTORY PADA PEMBELAJARAN BILANGAN NEGATIF BERDASARKAN TEORI SITUASI DIDAKTIS DI SEKOLAH MENENGAH
}

\section{HYPOTHETICAL LEARNING TRAJECTORY OF NEGATIVE NUMBERS BASED ON THEORY OF DIDACTICAL SITUATION FOR SECONDARY SCHOOL}

\author{
Nyiayu Fahriza Fuadiah \\ Pendidikan Matematika, Universitas PGRI Palembang \\ n_fahriza@yahoo.co.id
}

\begin{abstract}
Abstrak
Penelitian ini bertujuan untuk mendesain Hypothetical Learning Trajectory (HLT) pada pembelajaran bilangan negatif sebagai hasil dari tahap pertama Didactical Design Research yaitu Analisis Prospektif. HLT ini merupakan tindak lanjut dari hasil identifikasi Learning Obstacle yang yang dilakukan peneliti dalam pembelajaran bilangan negatif yang terintegrasi dalam materi Bilangan Bulat di kelas 7 sekolah menengah pertama. Observasi mendalam terhadap proses belajar mengajar di kelas yang diamati peneliti memperlihatkan kesulitan guru dalam menanamkan konsep bilangan negatif dan operasi bilangan yang melibatkan bilangan negatif serta beberapa kesalahan konstruksi konsep yang dialami oleh siswa. Istilah HLT merujuk pada rencana pembelajaran berdasarkan antisipasi belajar siswa yang mungkin dicapai dalam proses pembelajaran yang didasari pada tujuan pembelajaran matematika yang diharapkan pada siswa, pengetahuan, dan perkiraan tingkat pemahaman siswa, serta pilihan aktivitas matematika secara berurut. HLT ini disusun berdasarkan analisis terhadap Learning Obstacle, tahap berpikir siswa, dan analisis terhadap kurikulum dengan tetap berpijak pada konsep materi yang harus dipahami siswa.
\end{abstract}

Kata Kunci: Hypothetical Learning Trajectory, Teori Situasi Didaktis, Bilangan Negatif, Pembelajaran Matematika

\begin{abstract}
This research aims to design Hypothetical Learning Trajectory (HLT) on learning of negative numbers as a result of the first stage on Didactical Design Research specifically in Prospective Analysis. This HLT is a follow up of the results of the identification of the Learning Obstacle conducted by researcher in learning negative numbers that integrated in the material Integer in the 7th grade secondary school. From the observations conducted by researcher on the teaching and learning process in the classroom showed the difficulties of teachers in embedding the concept of negative numbers and arithmetic operations involving negative numbers and several construction errors of concepts that experienced by the students. Term of HLT refers to a lesson plan based on the anticipation of student learning possibly achievable in the learning process which is based on mathematics learning goals expected on students, knowledge, estimates of the level of students understanding, and the selection of mathematical activity sequentially. This HLT is compiled based on an analysis of the Learning Obstacle, level of students thinking, and analysis of the curriculum that standing on the concept that must be understood by the students.
\end{abstract}

Keyword: Hypothetical Learning Trajectory, Theory of Didactical Situation, Negative Numbers, Mathematics Learning 


\section{Pendahuluan}

Dalam memahami matematika, proses belajar dan tingkat berpikir yang disebut sebagai lintasan belajar (learning trajectory) menjadi hal yang harus diperhatikan untuk mencapai tujuan yang diharapkan (Clements dan Sarama, 2004). Clements dan Sarama (2004) lebih lanjut menjelaskan bahwa lintasan belajar adalah gambaran pemikiran siswa saat proses pembelajaran berupa dugaan dan hipotesis dari serangkaian desain pembelajaran untuk mendorong perkembangan berpikir siswa agar tujuan pembelajaran matematika dapat tercapai sesuai dengan yang diharapkan.

Penggunaan istilah learning trajectory (LT) pertama kali diterapkan dalam proses pembelajaran matematika oleh Simon (1995). la menggambarkan perhatiannya pada cara guru mengajar dan harapannya untuk memberikan informasi kepada siswa bagaimana berpikir tentang konsep matematika, sertamenciptakan suatu pengalaman baru atau masalah yang dirancang untuk membantu proses pemahaman siswa. Dalam hal ini guru terlibat interaksi dengan siswa secara langsung, mengamati apa yang telah dipahami siswa, menerapkan ide-idenya tentang jenis tugas dan masalah yang mungkin membawa siswa ke pemahaman konsep baru. Maloney dan Confrey (2013) menjelaskan bahwa LT dapat menjadi fondasi strategi penilaian untuk melihat kemajuan siswa dan mengindentifikasi kelemahan siswa secara individu maupun kelompok sehingga guru dapat menentukan solusinya. Simon (Sztajn et.al, 2012) mengekspresikan Hypothetical Learning Trajectory (HLT) sebagai gambaran proses pembelajaran ketika siswa mengalami proses pembelajaran mulai dari awal sampai tercapainya tujuan pembelajaran. Istilah HLT merujuk pada rencana guru berdasarkan antisipasi belajar siswa yang mungkin dicapai dalam proses pembelajaran yang didasari oleh tujuan pembelajaran matematika yang diharapkan pada siswa, pengetahuan dan perkiraan tingkat pemahaman siswanya, serta pilihan aktivitas matematika secara berurut.

Berkaitan dengan lintasan belajar, Simon (dalam Daro et.al, 2011:18) menyatakan bahwa guru hendaknya menyusun rencana pembelajaran yang sesuai dengan lintasan belajar siswa. Rencana pembelajaran (lesson plan) merupakan suatu skenario pembelajaran yang disusun oleh guru berdasarkan antisipasi terhadap kemungkinan perkembangan belajar siswa untuk mencapai tujuan pembelajaran berdasarkan pengetahuan yang telah dimiliki oleh siswa dan perkiraan pemahaman siswa terhadap suatu materi (Daro et.al, 2011:18). Fungsi utama dari rencana pembelajaran sendiri adalah untuk memberikan siswa kesempatan belajar sehingga guru harus merencanakan apa yang mungkin akan terjadi selama proses pembelajaran (Sanchez dan valcarcel, 1999).

Keberadaan buku teks tidak lepas dari rencana pelajaran yang disiapkan oleh 
guru sebagai bagian dari bahan ajar. Berdasarkan observasi penulis terhadap beberapa buku teks matematika, bukubuku pelajaran kelas matematika 7 cenderung menekankan pada prosedur dengan menghafal rumus matematika dari pada proses melalui pemecahan masalah (Fuadiah, 2015). Sebagai contoh, sebuah studi kasus yang dilakukan oleh peneliti pada 96 siswa kelas 7 Sekolah Menengah Pertama di kota Palembang yang telah mempelajari operasi bilangan bulat, terdapat $74,9 \%$ siswa yang mengalami kendala dalam operasi hitung bilangan bulat, seperti menyatakan bahwa operasi dari $-4+5$ sebagai -9. Salah satu penyebab kesalahan ini adalah informasi yang mereka tafsirkan sebagai: bilangan negatif ketemu bilangan positif maka akan menghasilkan bilangan negatif. Formula ini merupakan prosedur dari operasi perkalian yang biasanya terdapat dalam buku teks matematika yang kemudian disampaikan oleh guru dan dihafalkan oleh siswa. Akibatnya siswa kemudian menganalogikan konsep ini kepada operasi penjumlahan.

Konsep pengurangan yang bermakna 'mengambil' tidak berlaku bagi siswa ketika menghadapi, misalnya, 2 - (-5). Berdasarkan pengamatan peneliti, terdapat kebingungan yang dialami siswa dalam memaknai 'mengambil -5 ' dan ketika - (-5) diubah menjadi +5 . Dalam hal ini terdapat kerancuan siswa dalam memaknai tanda minus sebagai simbol operasi pengurangan dan sebagai lambang bilangan negatif. Hal ini juga diungkapkan oleh Subanji (2015:60), dari temuan penelitiannya yaitu terdapat proses yang salah dalam mengonstruksi konsep operasi bilangan bulat, yaitu menyamakan antara lambang bilangan dan operasi bilangan pada simbol "-“ (minus). Berdasarkan wawancara peneliti terhadap guru matematika yang mengajar di kelas tersebut, sebenarnya ia pun mengalami kendala bagaimana menyampaikan konsep bilangan negatif ini kepada siswa.

Berkenaan dengan pembelajaran bilangan negatif, Blair et.al (2012) berpendapat bahwa tidak seperti bilangan positif, bilangan negatif tidak memiliki rujukan persepsi yang jelas, dan karena itu, para siswa harus berusaha lebih keras belajar mengenaibilangan negatif Penelitian yang telah dilakukan yang berkaitan dengan bilangan negatif menunjukkan bahwa bilangan negatif telah menimbulkan persoalan tersediri bagi banyak siswa tingkat menengah (Almeida dan Bruno, 2014). Permasalahan bilangan negatif ini diakibatkan oleh struktur, posisi yang tidak diketahui, jenis bilangan ataukonteksnya. Altiparmak dan Ozdogan (2010) juga mengungkapkan kesulitan dalam memahami konsep bilangan negatif yaitu pemahaman sistem bilangan, arah dan banyaknya, pemahaman mengenai operasi aritmatika, dan kesulitan yang berkaitan dengan tanda negatif. Ketiga hal ini berhubungan erat dengan konsep abstrak. Konsep abstrak bilangan negatif inilah yang diketahui sebagai menyebabkan hambatan 
epistemologis dalam pengembangan pengetahuan matematika (Larsen, 2012).

Brousseau (2002) menegaskan bahwa peran guru adalah untuk mendorong ideide matematika dalam konteks melalui proses penyelidikan. Tidak dipungkiri bahwa proses ini memerlukan rencana pembelajaran yang sangat kompleks. Rencana pembelajaran yang kurang mempertimbangkan keragaman respon siswa atas situasi didaktis yang dikembangkan dapat berdampak terhadap rangkaian situasi didaktis yang dikembangkan berikutnya yang kemungkinan besar tidak lagi sesuai dengan keragaman lintasan belajar (learning trajectory) masing-masing siswa (Suryadi, 2013). Oleh karena itu, perlu kita sadari sepenuhnya bahwa penting bagi guru untuk merancang pembelajaran dengan desain didaktis untuk mengantisipasi semua tanggapan siswa yang mungkin pada situasi didaktis (Suryadi, 2013). Penerapan teori situasi didaktis melalui desain situasi didaktik yang diciptakan oleh guru dalam kegiatan pembelajaran di kelas diharapkan untuk mengembangkan potensi siswa, yang dapat membangun pengetahuan mereka sendiri melalui serangkaian proses abstraksi. Tindakan dan umpan balik melalui strategi yang tepat akan memungkinkan pembentukan pengetahuan baru pada siswa.

Theory of Didactical Situation in Mathematics (TDSM) diperkenalkan oleh Brousseau pada tahun 1986. Langkah pertama dalam pendekatan teoritis ini adalah analisis segitiga didaktis, yang dikenal sejak tahun 1982 ketika pertama dimunculkan oleh Yves Chevallard (Manno, 2006). Implikasi ganda pada segitiga tersebut menunjukkan bahwa terdapat interaksi yang kompleks yang saling timbal balik antara Guru - Siswa Pengetahuan (materi). Manno (2006) menjelaskan bahwa peran guru adalah untuk memungkinkan transposisi didaktis; dengan kata lain, guru harus mengubah"pengetahuan" yang berasal dari penemuan ke dalam"pengetahuan yang diajarkan" (salah satu kegiatan dalamkelas sehari-hari) melalui langkah berikutnya antara lain"pengetahuan yang harusdiajarkan". Lebih jauh TDSM, menurut Artigue (1994), bertujuan untuk memodelkan situasi mengajar sehingga dapat dikembangkan dengan tahapan yang terkontrol.

Merujuk pada Brousseau, Artigue et.al (2014: 49-50) menjelaskan karateristik dari TDSM. Karakteristik TDSM pertama adalah perhatiannya pada matematika dan epistemologi-nya. Dalam hal ini konversi didaktis dari gagasan tentang kendala epistemologis, dan juga melalui gagasan situasi fundamental. Mengacu pada penelitian Bachelard yang mengindentifikasi hambatan epistemologis alam dalam ilmu fisika, Brousseau (2002:83) meluaskan penerapannya pada aspek didaktis dari matematika, mendefinisikan kendala epistemologis sebagai bentuk pengetahuan yang telah relevan dan berhasil dalam konteks tertentu. Karakteristik penting kedua di 
TDSM terkait dengan karakteristik epistemologis yaitu pengetahuan matematika adalah sesuatu yang memungkinkan kita untuk bertindak atas lingkungan. Karakteristik ini mencerminkan di TDSM melalui perbedaan antara tiga jenis tertentu situasi: situasi dari tindakan, situasi formulasi, dan situasi validasi (Brousseau, 2002; Kislenko, 2005; Perrin-Glorian, 2008; Manno, 2006; Wisdom, 2014). Karakteristik penting yang ketiga mengacu pada dimensi kognitif siswa, terutama dengan kombinasi daridua proses adaptasi dan akulturasi.

Berdasarkan pemaparan tersebut, kajian utama dalam penelitian ini adalah bagaimanakah HLT pada pembelajaran bilangan negatif berdasarkan teori situasi didaktik yang sesuai dengan kebutuhan dan tingkat berpikir siswa pada siswa sekolah menengah. Desain situasi didaktis yang terintegrasi dalam HLT ini diharapkan dapat membantu siswa maupun guru dalam menanamkan konsep bilangan negatif dan operasi bilangan bulat pada kegiatan belajar mengajar di dalam kelas. HLT ini juga diharapkan juga dapat dikembangkan menjadi Lesson Design sesuai dengan situasi didaktis dan pedagogis yang berkembang selama proses pembelajaran.

\section{Metode}

HLT disusun berdasarkan analisis terhadap Learning Obstacle, tahap berpikir siswa, dan analisis terhadap kurikulum dengan tetap berpijak pada konsep materi. yang harus dipahami siswa. Bersadarkan LO, peneliti menemukan beberapa kendala epistemologis yang dialami siswa, seperti mencampur adukkan tanda minus (-) sebagai tanda bilangan dan tanda operasi bilangan, keliru dalam mengurutkan bilangan negatif, kesalahan dalam memaknai konteks yang berkaitan dengan bilangan negatif, dan yang paling banyak terjadi adalah kesalahan dalam operasi hitung bilangan serta memodelkan suatu konteks dalam suatu bentuk operasi hitung (Fuadiah, 2015). HLT didesain berdasarkan tujuan pembelajaran yang ingin dicapai, aktivitas yang mendukung tujuan, dan hipotesis matematis berupa konjektur yang diharapkan terjadi pada siswa sesuai dengan kemampuan berpikirnya (Simon, 1995). Oleh karena itu HLT disusun dengan memperhatikan tahap alur pikir siswa dan konsep materi yang harus dibangun oleh siswa. Kedua hal ini harus saling bersinergi agar aktivitas yang didesain sejalan dengan keduanya sehingga didapatkan suatu desain pemembelajaran yang sesuai dengan kebutuhan belajar dan karakteristik siswa. Tahap yang dilakukan peneliti dalam menyusun HLT sebagai berikut:

1. Kajian teoritis mengenai karakteristik berpikir siswa dalam rentang usia 11 13 tahun (kelas 7).

2. Mempelajari sejarah dan kajian mendalam teori mengenai konsep bilangan negatif serta penelitian yang pernah dilakukan mengenai bilangan negatif. 
3. Mengkaji kurikulum dan silabus bukubuku teks matematika yang digunakan siswa kelas VII. Termasuk dalam kegiatan ini mengkaji metode, pendekatan, atau metode yang digunakan untuk menyampaikan konsep bilangan negatif

4. Menelaah kembali aspek-aspek learning obstacles yang terjadi dalam proses belajar. Hal ini perlu dilakukan agar nantinya situasi didaktis yang diciptakan dapat meminimalisir learning obstacles baik dari aspek siswa maupun guru.

5. Mengkaji situasi didaktis apa yang akan dibangun, memprediksi respon siswa yang mungkin terjadi terhadap situasi yang diciptakan, dan menentukan antisipasi didaktis maupun pedagogis terhadap respon tersebut.

\section{Hasil dan Pembahasan}

\section{A. Bilangan Negatif dalam Kurikulum Matematika}

Tabel 1.

Silabus Bilangan Bulat Kelas 7

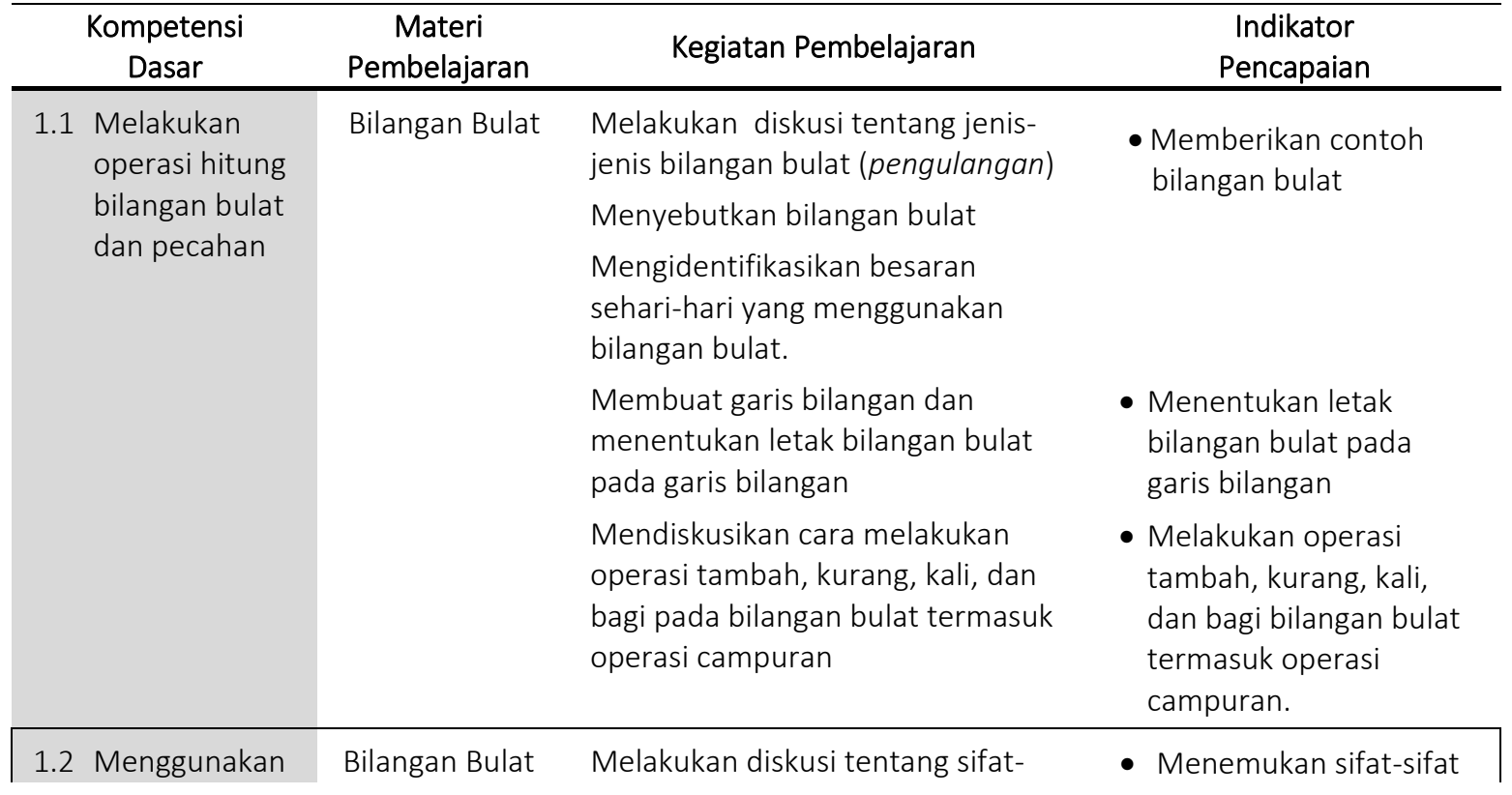

Di Indonesia secara spesifik materi bilangan negatif merupakan bagian dari materi Bilangan dalam Kurikulum Tingkat Satuan Pendidikan (Kurikulum 2006) maupun dalam Kurikulum 2013. Bilangan merupakan materi pada semester ganjil kelas 7 dengan standar kompentensi memahami sifat-sifat operasi hitung bilangan dan penggunaannya dalam pemecahan masalah. Dalam standar ini materi yang dipelajari mencakup bilangan bulat dan pecahan. Konsep bilangan negatif terintegrasi dalam bilangan bulat maupun pecahan. Peneliti memberi penekanan khusus kepada bilangan negatif, mengingat konsep ini merupakan konsep abstrak pertama kali yang diberikan kepada siswa. Posisi materi bilangan bulat negatif dalam materi bilangan bulat dalam silabus mata pelajaran matematika kelas 7 secara garis besar dapat dilihat pada tabel 1 . 


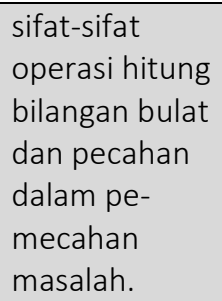

sifat operasi tambah, kurang, kali, bagi pada bilangan bulat(pengulangan) operasi tambah, kurang, kali, bagi, pada bilangan bulat.
Melakukan diskusi cara menggunakan operasi hitung tambah, kurang, kali atau bagi dalam menyelesaikan masalah sehari-hari yang berkaitan dengan bilangan bulat
- Menggunakan sifat-sifat operasi bilangan bulat untuk menyelesaikan masalah yang berkaitan dengan kehidupan sehari-hari.

\section{B. Penyusunan HLT}

Bersadarkan silabus dan tujuan pembelajaran, peneliti menyusun draft awal HLT bilangan bulat negatif. HLT memuat tiga komponen utama learning trajectory yaitu: 1) tujuan pembelajaran yang ingin dicapai, 2) aktivitas yang mendukung tujuan, dan 3) dugaan-dugaan matematis sebagai hasil aktivitas. Aktivitas yang diciptakan nanti dilandaskan pada level berpikir dan konsep materi dengan bantuan media dan konteks yang sesuai dengan karakter siswa. Draft awal HLT ini mengacu pada konten materi bilangan bulat sesuai dengan KTSP dan Kurikulum 2013 yang diberi penekanan materi sesuai dengan identifikasi learning obstacles yang peneliti lakukan sebelumnya. Berikut draft awal HLT:

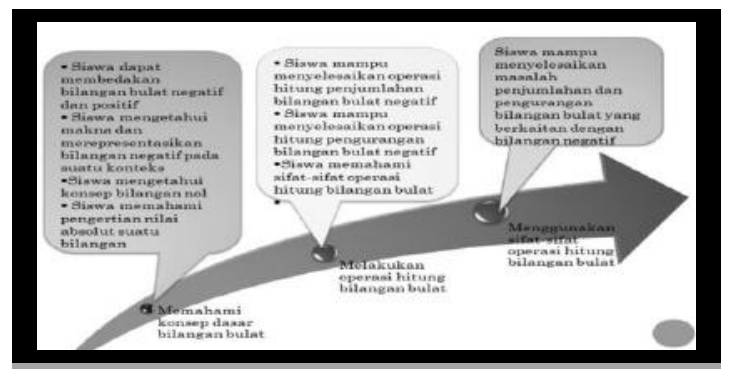

Gambar 1. Draft awal HLT
Penyusunan HLT juga harus memperhatikan tahap berpikir serta perkembangan kognitif siswa. Dalam aspek tahap berpikir, Gravemeijer (1998) menjabarkan level conceptual leaning trajectory yaitu: 1) Situational Level, siswa berada dalam suatu konteks situasi yang spesifik; 2) Referential Level, model dan strategi mengacu pada situasi yang dijelaskan dalam masalah; 3) General Level, fokus matematika pada penguasaan strategi yang mengacu untuk konteks; dan 4) Formal Level, bekerja dengan prosedur konvensional dan notasi. Setelah melalui empat level ini, siswa harus mampu menerapkan konsep-konsep yang diperoleh untuk masalah baru dalam konteks yang berbeda. Beberapa topik matematika setelahnya memerlukan matematisasi vertikal (melalui proses abstraksi, menskemakan, atau generalisasi).

Poehler dan Prediger (2014) kemudian menjabarkan tahapan tersebut menjadi enam level tahap berpikir yang dilalui oleh seorang siswa kelas 7 dalam memahami suatu materi. Tahap ini dimulai dari berpikir secara informal yang dimulai dari 
pencarian yang dilakukan siswa sendiri sampai ke tahap formal dimana siswa dapat menggunakan konsep untuk memecahkan masalah. Pada tahap ini siswa tidak lagi bergantung pada konteks yang telah diberikan, namun dapat mengabstraksi sendiri solusi suatu masalah dengan menggunakan konsep yang tepat. Level tahap berpikir tersebut adalah:

Level 1: Informal thinking starting from students' resources, membangun makna suatu konsep dengan menggali kemampuan siswa melalui konteks informal

Level 2: First informal strategies and basic meaning, siswa mengembangkan strategi informal dan makna awal yang ia pahami dari kegiatan sebelumnya.

Level 3: Procedures for standard problem types, siswa menentukan strategi untuk menyelesaikan operasi hitung sederhana.

Level 4: Extending the repertoire, memperluas strategi ke masalah lain dengan melakukan manipulasi dan perbandingan.

Level 5: Identification of different problem types, Mengidentifikasi berbagai jenis masalah (termasuk masalah non standar) dalam konteks yang beragam.

Level 6: Flexible use of concepts and strategies, memecahkan masalah yang lebih kompleks dengan konteks yang tidak biasa.

Berdasarkan tahapan berpikir tersebut dan konsep bilangan negatif, draft HLT kemudian dikembangkan melalui situasi didaktis.

\section{Integrasi Situasi Didaktis dalam HLT}

Berdasarkan studi yang dilakukan peneliti terhadap learning obstacles, maka siswa perlu diperkenalkan terlebih dahulu dengan makna tanda minus (-) itu sendiri (symbol sense) agar siswa dapat memaknai tanda minus sesuai dengan fungsinya. Hal ini sejalan dengan hasil penelitian Subanji (2015) mengenai kesalahan konseptual yang terjadi pada siswa pada operasi bilangan bulat mengenai kerancuan siswa mengartikan simbol minus sebagai operasi pengurangan dan sebagai lambang bilangan negatif. Penelitian yang dilakukan oleh Lamb et.al (2012) menemukan bahwa hanya $25 \%$ dari siswa sekolah menengah yang mereka teliti yang dapat mengindentifikasi dengan benar bahwa - 4 lebih besar dari -4, para siswa tersebut tidak menyadari bahwa sebenarnya mereka memiliki informasi yang cukup untuk menentukan bilangan yang lebih besar dari $-x$ atau $x$. Pada desain ini symbol sense of minus sign diberikan pada tahap awal pembelajaran agar tidak terjadi kesalahan konsep tanda minus pada tahap pembelajaran selanjutnya.

Tanda minus sendiri memiliki tiga fungsi yaitu, sebagai fungsi uner, biner, dan simetris (Bofferding, 2014; Vlassis, 2008). Bofferding (2014) kemudian menyatakan "minus" mengacu pada simbol "- " memiliki arti sebagai "pengurangan" (makna biner dari tanda minus), "tanda minus" sebagai makna uner dari bilangan negatif, dan lawan sebagai makna dari fungsi simetris. Makna tersebut dapat digunakan secara fleksibel sesuai dengan konteks yang terjadi. Oleh karena itu 
situasi didaktis yang dibangun mengacu pada fenomena keseharian dengan memberikan pertanyaan-pertanyaan yang merangsang kemampuan berpikir anak dalam membedakan masing-masing fungsi tanda minus. Misalnya untuk memecahkan masalah berapakah jarak kota A ke Kota B maka tanda "-" berfungsi sebagai pengurangan.

Berkenaan dengan konsep bilangan negatif dalam desain tersebut, peneliti mengadopsi dari tiga dimensi konsep bilangan negatif yang dikemukakan oleh Altiparmak dan Ozdogan (2010) yaitu: 1) the negative case yaitu makna suatu bilangan, arah, dan kuantitas bilangan (numerical system), 2) meaning of the calculations and number line yaitu operasi hitung yang menghubungkan antara apa yang telah pahami dengan dunia nyata serta penggunaan garis bilangan sebagai ilustrasi konkrit yang menggambarkan konteks dari suatu situasi. dan 3) interpretasion and explanation, yaitu bagaimana siswa memahami hubungan bilangan negatif dengan suatu konteks, menafsirkan, membuat generalisasi, menentukan operasi hitung, dan menghubungkan suatu konteks dengan konteks lainnya.

Untuk mendukung pemahaman konsep ini kepada siswa, konteks dirancang sedemikian rupa untuk merepresentasikan suatu masalah yang berkaitan erat dengan bilangan negatif. Situasi "Air and Sea" merupakan konteks yang cocok untuk menggambarkan garis bilangan dan merepresentasikan perbedaan bilangan negatif, nol, dan bilangan positif. Berdasarkan Altiparmak dan Ozdogan (2010), garis bilangan dalam hal ini merupakan model yang digunakan siswa untuk memecahkan suatu masalah dengan tujuan mempermudah operasi hitung. Namun demikian, penggunaan model selain garis bilangan, karena keterbatasannya, juga diperlukan agar abstraksi pada siswa dapat berkembang. Untuk itu, peneliti menggunakan teknik "Bola Positif dan Negatif" dalam mengeksplorasi operasi hitung bilangan. Melalui teknik ini siswa dapat diarahkan pada sifat-sifat operasi hitung bilangan.

Berkaitan dengan situasi didaktis yang dirancang oleh guru, Brousseau (2002) menjelaskan bahwa interaksi antara siswa dan guru dalam sebuah situasi didaktis memberikan kontribusi terhadap aturan dan modifikasi norma-norma sosial untuk kegiatan matematika yang tercermin dalam sebuah kontrak didaktis. Brousseau juga menekankan bahwa siswa harus memiliki kebebasan untuk membuat respon terhadap situasi berdasarkan konteks pengetahuan yang telah diketahui dan perkembangan pemahaman matematis siswa.

Kegiatan pembelajaran berdasarkan lintasan belajar menghendaki guru berinteraksi langsung dengan siswa, mengamati apa yang telah dipahami siswa, menerapkan ide-idenya tentang jenis tugas, dan masalah yang mungkin membawa siswa ke suatu konsep baru. Berdasarkan hal tersebut HLT ini nantinya akan berdampingan dengan Lesson Design yang merinci secara jelas kegiatan pembelajaran, input guru untuk mencapai 
tujuan pembelajaran melalui suatu situasi didaktis, respon siswa yang mungkin terjadi serta antisipasi didaktis dan pedagogis yang dapat dilakukan guru.

\section{Penutup}

Mengajar adalah suatu proses yang menuntut guru untuk merencanakan tentang apa yang mungkin akan terjadi selama proses kegiatan belajar mengajar nantinya. Dengan demikian perlu disadari sepenuhnya bahwa penting bagi guru merancang dan merencanakan pembelajaran dengan desain didaktis yang dapat mengantisipasi semua kemungkinan respon siswa pada suatu situasi didaktis. Perencanaan yang sesuai dengan lintasan belajar siswa memungkinkan untuk melakukan tindakan pembelajaran sesuai kebutuhan siswa. Suryadi (2013) menyebutkan sintesis hasil pemikiran guru berdasarkan berbagai prediksi, sesuai dengan lintasan belajar siswa yang mungkin akan terjadi pada peristiwa pembelajaran, sebagai Antisipasi Didaktik dan Pedagogis (ADP).

HLT yang didesain peneliti ini dapat dikembangkan melalui proses validasi pada aspek konstruk dan kontenserta diuji serta disempurnakan melalui ekperimen pengajaran di kelas melalui pilot dan teaching experiment yang merupakan tahap Didactical Design Research berikutnya yaitu Analisis Metapedadidaktif. HLT merupakan proses pelaksanaan pembelajaran yang dipandu oleh suatu instrumen dalam suatu desain pembelajaran yang dapat diuraikan dan diperbaiki selama proses penelitian berjalan (Gravemeijer dan Cobb, 2006). Dengan demikian, HLT ini dapat dikembangkan lagi sesuai dengan teori situasi didaktis. Melalui observasi terhadap siswa selama kegiatan pembelajaran, diharapkan didapatkan suatu perangkat merupakan lintasan belajar teraktualisasi (Actualized Learning Trajectory).

\section{Daftar PUstaka}

Almeida, R., dan Bruno, A. (2014). Strategies of pre-servise primary school teachers for solving addition problems with negative numbers. International Journal of Mathematical Education in Science and Technology, 45(5), 719-737. http://dx.doi.org/10.1080/00207399 9287482.

Altiparmak, K., dan Ozdogan, E. (2010). A Study on the teaching of the concept of negative numbers.International Journal of Mathematical Education in Science and Technology, 41(1): 31-47. http://dx.doi.org/10.1080/00207390 903189179.

Artigue, M. (1994). Didactical Engineering as a framework for the conception of teaching product. In R. Biehler et al. (Eds.), Didactic of mathematics as a scientific discipline (pp. 27-39). Dorddrecht: Kluwer Academic Publishers.

Artigue, M., Haspekian, M., dan CorblinLenfant, A. (2014). Introduction to the theory of didactical situation (TDS). In: Ahsbahs dan Prediger (Eds.),Networking of theories as a research pratice in mathematics education (47 - 65). Switzerland: Springer International Publishing. 
Blair, K. P., Rosenberg-Lee, M., Tsang, J.M., Schwartz, D.L., dan Menon, V. (2012). Beyond natural numbers: negative number representation in parietal cortex. Frontiers in Human Neuroscience, 6(7), 1-17. http://dx.doi.org/10.3389/fnhum.201 2.0000.

Bofferding, L. (2014). Negative integer understanding: Characterizing first graders' mental models. Journal for Research in Mathematics Education, 45(2), 194-245. http://dx.doi.org/10.5951/iresemathe duc.45.2.0194.

Brousseau, G. (2002). Theory of didactical situation in mathematics.Kluwer Academic Pulishers.

Clements, D., dan Sarama, J. (2004). Learning trajectories in mathematics education. Mathematical Thinking and Learning, 6(2), 81-89.

Daro, P., et.al. (2011). Learning trajectories in mathematics: A foundation for standards, curriculum, assessment, and instruction.USA: Consortium for Policy Research in Education.

Fuadiah, N. F. (2015). Epistemological obstacles on mathematics'learning in junior high school students: a study on the operations of integer material. In Proceeding of International Conference On Research, Implementation And Education of Mathematics And Sciences 2015 (ICRIEMS 2015), Yogyakarta State University, 17-19 May 2015. Fakultas MIPA Universitas Negeri Yokyakarta.

Gravemeijer, K. (1998). Developmental Research as a Research Method. Dalam J. Kilpatrick dan A. Sierpinska (Eds.), What is research in mathematics education and what are its results? (hal.277-295). Dordrecht: Kluwer.

Gravemeijer, K., dan Cobb. P. (2006). Design research from a learning design perspective. Dalam Jan van den Akker, et. Al. Educational Design Research. London: Routlege.

Kislenko, K. (2005.) Student's beliefs about mathematics from the perspective of the theory of didactical situations. Dalam C. Winslow (ED.), Didactic of mathematics-the French way (83-96). Center For Naturfagenes Didaktis University of Copenhagen.

Lamb, L. L., Bishop, J. P., Philipp, R. A., Schappelle, B. P., Whitacre, I., dan Lewis, M. (2012). Developing symbol sense for the minus sign. Mathematics Teaching in the Middle School, 18(1), 5-9.

Larsen, J. (2012). Epistemological obstacles of negative numbers. Vector: The Official Journal of the BC Association of Mathematics Teachers, 53(2), 5660 [online]. Retrieved from https://www.researchgate.net/public ation/274310485 Epistemological Ob stacles of Negative Numbers

Maloney, A. dan Confrey, J. (2013). A Learning trajectory framework for the mathematics common core: turnonccmath for interpretation, instructional planning, and collaboration. 17th annual conference of the association of mathematics teacher educators. Orlando: AMTE.

Manno, G. (2006). Embodiment and adidactical situation in the teachinglearning of the perpendicular straight lines concept. Disertasi. Departement of Didactic Mathematics Comenius University Bratislava.

Sanchez dan Varcarcel. (1999). Science teachers' views and practices in 
planning for teaching. Journal of Research in Science Teaching, 36(4), $493-513$.

Simon, M. A. (1995) Reconstructing mathematics pedagogy from a constructivist perspective. Journal for Research in Mathematics Education, 26, 114-145.

Subanji. (2015). Teori Kesalahan Konstruksi Konsep dan Pemecahan Masalah Matematika. Malang: Universitas Negeri Malang.

Suryadi, D. (2013). Didactical Design Research (DDR) dalam pengembangan pembelajaran matematika. Prosiding Seminar Nasional Matematika dan Pendidikan Matematika. Bandung: STKIP Siliwangi.

Sztajn, P., Confrey, J., Holt Wilson, P., dan Edgington, C. (2012). Learning trajectory based instruction: toward a theory of teaching. Educational Researcher, 41(5), 147-156.

Pöhler,B., dan Prediger, S. (2014). Intertwining lexical and conceptual learning trajectories - A design research study on dual macro scaffolding towards percentages. Eurasia Journal of Mathematics, Science dan Technology Education, 11(6), 1697-1722.

Perrin-Glorian, M.J. (2008). From producing optimal teaching to analysing usual classroom situations development of a fundamental concept in the theory of didactic situations: the notion of milieu. [Online]. Retrieved from: https://www.unige.ch/math/EnsMath /Rome2008/WG5/Papers/PERRIN.pdf Vlassis, J. (2008). The role of mathematical symbols in the development of number conceptualization: The case of the minus sign. Philosophical Psychology, 21(4), 555-570. http://dx.doi.org/10.1080/095150808 02285552.

Wisdom, N. J. (2014). Meta-didactical slippages: a qualitative case study of didactical situations in a ninth grade mathematics classroom. Disertasi. Departement of Middle-Secondary Education and Instructional Technology Georgia State University.

\section{Riwayat Hidup PENULIS}

\section{Nyiayu Fahriza Fuadiah, S.Si., M.Pd.}

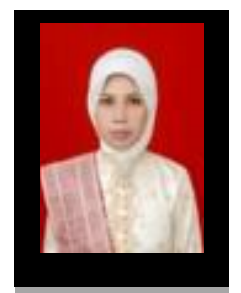

Lahir di kota Padang, Sumatera Barat, 10 September 1975. Penulis merupakan staf pengajar pada Program Studi Pendidikan Matematika di Fakultas Keguruan Ilmu dan Pendidian di Universitas PGRI Palembang. Pendidikan S1 penulis tempuh pada Jurusan Matematika Universitas Sriwijaya dan lulus pada tahun 1998. Pada tahun 2009, penulis menyelesaikan pendidikan S2 pada Program Studi Pendidikan Matematika PPs Universitas Sriwijaya. Tahun 2014 sampai sekarang, penulis melanjutkan pendidikan S3 pada Departemen Pendidikan Matematika Sekolah Pascasarjana Universitas Pendidikan Indonesia. Seminar yang penulis ikuti diantaranya International Conference On Research, Implementation And Education of Mathematics And Sciences 2015 (ICRIEMS 2015), Universitas Negeri Yokyakarta dan Konferensi Nasional Matematika XVIII Tahun 2016 di Pekanbaru, Riau. 